\title{
LISBOA AFRICANA NO CINEMA: CONVERSAS EM SALA DE AULA SOBRE LI KÉ TERRA E CAVALO Dinheiro
}

\author{
Ana Cristina Pereira, Isabel Macedo \& Rosa Cabecinhas
}

\begin{abstract}
RESUMO
Hoje, através do cinema, televisão, videojogos, publicidade e outros meios audiovisuais, as imagens têm um papel importante na formação das nossas crenças, conceitos e sonhos. Possuindo um movimento intrínseco que frequentemente escapa ao nosso controlo, as imagens podem contribuir para difundir estereótipos sociais, que marcam as nossas visões do mundo. A recente produção cinematográfica portuguesa destaca visões polémicas da complexa realidade pós-colonial na sociedade contemporânea, devido aos choques de memórias sobre o passado colonial que instiga. O documentário Li ké terra (2010) e a ficção Cavalo Dinheiro (2014) constituem espaços/lugares de memória e de reconstrução histórica. Através de discussões de grupos focais examinamos como jovens estudantes constroem as suas perceções sobre o quotidiano dos "imigrantes" africanos em Portugal e as suas representações sobre "raça". A análise das discussões dos grupos focais permite a compreensão do modo como as memórias coletivas são (re)criadas em contextos pós-coloniais e uma reflexão crítica sobre conflitos (passados) e as relações intergrupais atuais. Esta análise qualitativa foi realizada com o recurso ao método indutivo-comparativo e também à análise crítica do discurso.
\end{abstract}

\section{Film screening African Lisbon: talking about LI KÉ TERRA AND HORSE MONEY IN CLASSROOMS}

\begin{abstract}
Today, through cinema, television, videogames, other audiovisuals and especially advertising, images have a role shaping beliefs, concepts and dreams. Most images have an inner action beyond our control, spreading social stereotypes that embody our visions of the world. Recent Portuguese film production highlight controversial visions of the complex post-colonial reality in contemporary society due to the clashes of memories about the colonial past that these films instigate. The documentary Li ké terra (2010) and the feature film Horse Money (2014) constitute places of memory and historical reconstruction: both films tell stories about Cape Verdean communities in Portugal, revealing present realities strongly influenced by a colonial History. Through focus group discussions about these films we examine how young students (re)construct their perceptions about the daily lives of African "immigrants" in Portugal and their representations of "race". These focus group discussions enabled us to scrutinize the way collective memories are (re)created in post-colonial contexts, and whether and how these memories enable the critical reflection about past conflicts and current intergroup relations. This qualitative analysis was carried out using the inductive-comparative method and the critical discourse analysis.
\end{abstract}




\section{Cinema, MEMÓRIA E (RE)CONFIGURAÇÃo DAS IDENTIDAdES}

O cinema é uma forma de arte e um poderoso meio de comunicação social que pela facilidade com que é reproduzido e distribuído consegue ser transversal social e culturalmente. Nessa medida, como outros média, o filme pode contribuir para a homogeneização de representações sociais, mas também pode desempenhar um papel importante na disseminação de representações sociais polémicas, promovendo assim a mudança social. Os regimes políticos tentaram ao longo da história colocar o cinema ao serviço dos seus interesses, e isto acontece tanto em práticas de regimes autoritários como em democracia. Os cineastas optam (de forma consciente ou não) por colaborar com o sistema político em que estão inseridos, ou tentam contrapor um discurso alternativo. Ao público cabe a responsabilidade de interpretar (produzir sentido sobre) os filmes, o que é uma tarefa interminável, dada a diversidade de leituras que uma mesma obra pode suscitar.

A colonização portuguesa de África foi sendo, de algum modo, documentada pelo cinema. Nas primeiras décadas do século XX foram feitos pequenos filmes com "nativos" em rituais, envergando trajes tradicionais, mostrando quão úteis eram aos colonos portugueses e como respeitavam a cultura portuguesa, mesmo sendo exóticos, excêntricos e estranhos (Matos, 2016). No entanto, foi apenas nos anos 1930, durante o Estado Novo, que o filme foi estrategicamente usado para reforçar o sentimento de identidade nacional (Piçarra, 2015) transformando o Império Colonial numa bandeira do orgulho nacional.

A Revolução dos Cravos, que ocorreu a 25 de abril de 1974, abriu as portas à democracia e também à negociação política que desembocou na independência das colónias portuguesas em África. Os anos seguintes foram caracterizados pela afirmação de uma liberdade criativa influenciada pelo cinema de auteur europeu, especialmente pela Nouvelle Vague, e uma consciência política revolucionária. No final da década de 1970 e especialmente durante os anos 1980, Portugal fez um esforço considerável para devir um país europeu de pleno direito e juntar-se à CEE (hoje UE). Sobre este assunto, Lemière (2006) refere que, em Portugal, a descolonização tardia foi seguida por um período de autorreflexividade em que a "nação" digeria uma realidade em que tinha ficado "pequena e pobre". Reforçando este sentimento a exigência institucional da Europa compelia o país a reconhecer a sua pequenez'.

Nos anos 1990, grupos minoritários com origem cabo-verdiana começaram a aparecer em filmes. Esta década deu origem a uma geração de cineastas formados pela

\footnotetext{
' A entrada de Portugal na Comunidade Económica Europeia (CEE), em 1986, resultou de vários anos de difíceis negociações com os restantes parceiros. A candidatura foi apresentada em 28 de março de 1977, mas foi necessário ultrapassar diversas dificuldades através de processos negociais que se arrastaram por oito anos e por oito governos portugueses. Sobre a mesa das negociações, entre outros temas, estiveram questões relacionadas com o comércio, a agricultura, as pescas e mesmo a emigração. O tratado de adesão de Portugal à CEE foi assinado em 12 de junho 1985 e o país integrou oficialmente a comunidade em 1 de janeiro de 1986 (Pinto, 2011).
} 
Escola Superior de Teatro e Cinema². Esta nova geração de realizadores ${ }^{3}$, foi herdeira de uma tradição de cinema purista, eclética e fortemente ideológica - teve como professores alguns dos realizadores do Novo Cinema português, mas chegou com a sua própria agenda e com o desejo de seduzir o público (Baptista, 2011). Na última década do século XX foram feitos filmes que pretendiam iluminar aspetos do quotidiano urbano e muitas vezes marginal, desafiando uma ideia de "nação" que exclui realidades plurais e periféricas.

Já no século XXI uma parte significativa dos filmes portugueses está comprometida com a promoção de uma visão sobre a sociedade portuguesa atual e a história portuguesa recente, que poderá questionar as conceções hegemónicas sobre a identidade portuguesa. Neste processo, as diásporas pós-coloniais jogam um papel catalisador, porque, através delas, o trânsito cultural e a tradução (Hall, 2005) de culturas e identidades é acelerado e destacado (tornado visível), mudando desse modo as culturas locais.

De acordo com Bhabha (1994), estes são tipos específicos de identidade da modernidade tardia, que têm intervenção direta na perceção espácio-temporal e na configuração atual da alteridade, representando o "intermediário": o outro não é "o" nem "outro", mas algo "além do intervalo" (1994, p. 103). Esses híbridos estão situados num "trânsito em que espaço e tempo se cruzam para produzir figuras complexas de diferença e identidade, passado e presente, dentro e fora, inclusão e exclusão" (1994, p. 19).

Em vez das "comunidades imaginadas" de cima para baixo, como Anderson (1983) descreveu, temos agora comunidades paralelas que coincidem no tempo e se relacionam umas com as outras e com o estado, numa espécie de rizoma de múltiplas identidades. No lugar da "identidade nacional", uma identidade híbrida cumulativa e performativa (Bhabha, 1994) aparece agora construída de baixo para cima e na prática diária, apesar de todas as contradições e riscos envolvidos no processo.

Há, no entanto, fatores que desempenham um papel importante na construção de identidades líquidas (Bauman, 2004) - o grau de liberdade individual nas negociações identitárias é limitado pelo estatuto social, sistemas de significado cultural e circunstâncias políticas (Cabecinhas, 2007) e o sistema global em que vivemos é hierarquizado racial, social e culturalmente (Bonilla-Silva, 2006). As sociedades contemporâneas relegam para a "cultura" as diferenças tradicionalmente atribuídas à "raça" e os indivíduos desenvolvem estratégias discursivas que lhes permitem não aparecer socialmente como racistas (van Dijk, 1984), mas isso não significa questionar os conceitos e estereótipos sociais herdados do passado. Segundo Wagner, Holtz e Kashima (2009), essencializar o "outro" é fundamental para a (re)construção das relações grupais. Este processo desempenha um papel central no racismo, na xenofobia, nos processos de desumanização, mas também nos processos de autoidentificação.

No ponto seguinte, após uma breve descrição de dois filmes: Li ké terra (2010) de Filipa Reis, João Miller Guerra e Nuno Baptista, e Cavalo Dinheiro (2014) de Pedro Costa,

\footnotetext{
${ }^{2}$ A Escola de Cinema foi fundada em 1973 com Alberto Seixas Santos como primeiro diretor, apoiado por Fernando Lopes, Paulo Rocha, António Cunha Telles, o técnico Costa Silva e os críticos Bérnard da Costa e Eduardo Prado Coelho, entre outros.

${ }^{3}$ Fernando Vendrell, Joaquim Sapinho, Margarida Vila Verde, Pedro Costa, entre outros.
} 
analisamos o diálogo que jovens portugueses estabelecem com estes filmes, que foram mostrados a diferentes audiências em contextos distintos. As mostras de cinema foram seguidas por debates com o objetivo de compreender como identidade e alteridade são (re)construídas atualmente através destes filmes.

\section{Li KÉ TERRA E CAVAlo Dinheiro: uma BREVe leitura}

Li ké terra (Filipa Reis, João Miller Guerra \& Nuno Baptista, 2010) é um documentário sobre uma geração de descendentes de imigrantes cabo-verdianos em Lisboa, que têm que lidar com um sistema burocrático que não os reconhece como portugueses apesar de terem nascido em Portugal, uma Escola que os força a decorar coisas em vez de as compreender, e a impossibilidade de arranjarem emprego sem terem os documentos de cidadania em ordem e sem concluírem a escolaridade. Nas palavras de Miguel Moreira, uma das duas personagens do filme: "isto é o que se chama um ciclo vicioso, certo?"

$\mathrm{Na}$ língua de Cabo Verde Li ké terra significa aproximadamente esta é a minha terra e, neste filme, refere-se ao bairro onde estes jovens vivem. O título tenta descrever o sentimento destas pessoas pelo seu bairro, mas em Li ké terra o problema é que legalmente elas não são dali. Miguel e Rúben têm metas: obter os documentos de cidadania; terminar o secundário; arranjar um emprego. Conseguir a cidadania portuguesa é o seu principal objetivo na vida.

Miguel e Rúben construíram uma representação de África como uma espécie de "paraíso perdido", um lugar de identificação emocional e por isso mesmo um lugar onde é (re)criada a identidade destes jovens. A história da família desempenha um papel central na forma como Miguel (re)constrói a sua identidade: "o jovem identifica-se culturalmente como cabo-verdiano. Para o Miguel Moreira, a educação, a música, a comida e mesmo a forma como expressa as suas emoções é cabo-verdiana" (Macedo, 2016, p. 279) e ele desenha continuamente narrativas e mitos sobre a cultura cabo-verdiana, construindo uma "comunidade imaginada" (Anderson, 1983; Hall, 1993) à qual ele sente que pertence.

Miguel Moreira, conhecido como Tibars, vive com a avó, desde que a mãe morreu e o pai foi preso e repatriado. Apesar de não ter documentos de cidadania portuguesa frequenta a Escola. Rúben Furtado, conhecido como Dibela, tem vários irmãos e irmãs, já não anda na Escola, e está a tentar obter a documentação requerida para conseguir a cidadania portuguesa.

Cavalo Dinheiro (Pedro Costa, 2014) pode ser descrito como um testemunho lírico que nos confronta com um sonho, ou um pesadelo, à medida que explora a memória e a loucura do cabo-verdiano Ventura, que veio para Portugal no princípio dos anos 1970, onde viveu a Revolução dos Cravos e trabalhou toda a sua vida. Cavalo Dinheiro fala-nos de uma geração de cabo-verdianos que deixou a sua terra natal, na perseguição de uma vida melhor e que perdeu a juventude e a saúde e, com frequência, a própria vida, enquanto tentava alcançar esse sonho. À medida que os dias passam os sonhos misturam-se com memórias, e as memórias de casa perdem a sua transparência, ainda que um destino comum una todas as personagens do filme. 
O destino dessa "outra metade" 4 é partilhado por Vitalina: ela casou-se em Cabo Verde e depois do casamento, o marido voltou para Portugal para trabalhar. Um dia, a irmã de Vitalina deu-lhe a notícia de que o seu marido emigrado estava morto. A mulher correu para a embaixada para obter os papéis, viajar e assistir ao funeral em Lisboa. $\mathrm{O}$ processo não foi suficientemente célere e a viagem não foi fácil, quando Vitalina chegou a Portugal, o seu marido já tinha sido enterrado. Vitalina partilha estas memórias dolorosas com Ventura e connosco, à medida que vai lendo documentos oficiais, sempre com uma voz sussurrada e sofrida.

Ventura que está doente, recupera visivelmente da sua doença depois de falar com Vitalina a primeira vez. Progressivamente transforma-se no marido dela, ao mesmo tempo que eles se transformam um no outro, num processo de troca de identidades que é conseguido através de uma não-realista e às vezes não coincidente troca entre imagens e texto e entre vozes e imagem: Vitalina e Ventura assumem a história um do outro como se tivessem ambos vivido as duas histórias. Mais uma vez, a ideia de destino comum emerge.

Este deslocamento do espaço e do tempo culmina na cena do elevador, onde Ventura fala com "fantasmas que o perseguem": os que estão vivos, os que estão mortos e os que são apenas símbolos. No final desta viagem catártica de elevador (que pode ser evidentemente uma metáfora para a sua mente) Ventura, que está prostrado a um canto, volta a sua cabeça para cima, para a câmara e diz: "esta é a história da vida jovem" (Cavalo Dinheiro, 2014).

Pedro Costa trabalhou com a comunidade das Fontainhas (agora Casal da Boba) desde meados dos anos 1990 e construiu uma obra cinematográfica baseada, do ponto de vista estético, numa tradição de cinema de auteur. A singularidade do trabalho de Costa, como um todo, resulta do seu duplo movimento (fugindo e aproximando-se do cinema): Costa afasta-se dos atuais modos de produção cinematográfica puxando-se para dentro da vida da comunidade, a ao mesmo tempo, constrói os seus filmes partindo das referências cinematográficas de que é herdeiro.

Filipa Reis é licenciada em administração de empresas tem uma pós-graduação em cinema e televisão. Fundou, com João Miller Guerra, uma empresa que desenvolve projetos cinematográficos e televisivos. Os cineastas inseriram-se em bairros sociais nos subúrbios de Lisboa, com o objetivo de mostrar essa realidade de dentro para fora. Desenvolvem o trabalho com as pessoas desses bairros, levando-as a narrar as suas histórias e aprofundando a questão da perspetiva. Li ké terra é um tipo de filme convencionalmente chamado "ficção do real": uma realidade encenada pelos próprios protagonistas.

Do ponto de vista estético Li ké terra e Cavalo Dinheiro revelam diferenças consideráveis, embora os temas e a metodologia de trabalho se intercetem. O interesse em analisar estes dois filmes juntos reside justamente na tentativa de compreender como resulta a relação com o público, particularmente no que diz respeito à leitura das representações raciais, de propostas tão distintas sob o ponto de vista artístico e político.

\footnotetext{
${ }_{4}$ Referência a How the other half lives: Studies among the tenements of New York (1890) que é um livro do fotógrafo e jornalista Jacob Riis sobre a vida quotidiana de imigrantes em Nova lorque no início do século XX. Algumas fotografias de Riis são usadas por Pedro Costa em Cavalo Dinheiro.
} 
Trata-se de perceber como o público, com as suas referências culturais e geracionais, dialoga com filmes tão diferentes. Em que medida essas referências se sobrepõem às propostas que as obras fazem e em que medida o Cinema tem a capacidade de levar os públicos a reconstruir as suas visões da realidade?

\section{LUGARES DE POIESIS - DISCUSSÕES DE GRUPOS FOCAIS}

Há uma espécie de continuidade entre os filmes Li ké terra e Cavalo Dinheiro: ambos se baseiam na realidade particular de pessoas de "origem cabo-verdiana" que vivem no Casal da Boba, em Lisboa. Em Li ké terra vemos as dificuldades, mas também as esperanças e os sonhos de dois rapazes, e em Cavalo Dinheiro somos confrontados com o desespero daqueles que poderiam ser seus pais, ou seus avós. Em ambos os filmes, as personagens são aprisionadas num mundo feito de estruturas que elas não podem controlar, nem melhorar, mesmo que as entendam.

Os dois filmes foram exibidos a uma audiência previamente selecionada, e depois foram promovidas discussões. Li ké terra foi visto e discutido por jovens que frequentavam escolas secundárias no norte de Portugal: 17 grupos focais com 129 estudantes do ensino secundário (84 sexo feminino e 45 sexo masculino), com idades entre os 16 e os 18 anos. Os grupos focais foram desenvolvidos nas disciplinas de Filosofia e História, de janeiro a abril de 2013. Cavalo Dinheiro foi apresentado em universidades do norte e centro de Portugal: 4 grupos focais com 73 alunos de licenciatura (40 do sexo feminino e 33 do sexo masculino) entre 17 e 21 anos. Os grupos focais foram desenvolvidos nos cursos de Sociologia e Teatro de outubro de 2014 a fevereiro de 2015.

Foram escolhidos estudantes do ensino secundário e do ensino superior, pois consideramos que eles envolvem uma faixa etária em que as identidades individuais estão (por diferentes razões e de modos distintos) numa fase crítica de construção (Fivush, 2008), onde a reflexão sobre o papel dos meios de comunicação na representação de certas realidades é crucial.

No documentário Li ké terra (2010) é central a discussão sobre as dificuldades dos afrodescendentes na obtenção da nacionalidade portuguesa, pois, como diz Filipa Reis, um dos principais objetivos do filme foi retratar essa realidade. No entanto, durante o processo de produção do filme, os realizadores "perceberam que existe um grande grupo de descendentes cabo-verdianos nestas comunidades que nasceram aqui e não se sentem portugueses", para Filipa Reis ${ }^{5}$ (2013) "é uma questão de identidade". À luz dessa descoberta, ela redefine as intenções:

eu pretendo partilhar pessoas... talvez pretenda desconstruir estereótipos no sentido em que me interessa imenso a complexidade das pessoas. As pessoas são muito complexas e não são só aquilo que nós às vezes olhamos para elas e imediatamente projetamos nelas, e, portanto, interessa-me trabalhar isso, interessa-me trabalhar a complexidade humana mais do que me interessa trabalhar as classes sociais. (Reis, 2013)

\footnotetext{
${ }^{5}$ Excerto da entrevista com Filipa Reis, realizada a 13 de abril de 2013, em Lisboa.
} 
Para Pedro Costa (2008) é importante "não esquecer que vivemos num planeta, que tem um nome, que tem uma forma particular de organização, e que aqui vivem,

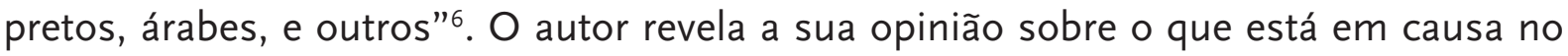
cinema:

enfim, eu acho que estou a falar de $90 \%$ da humanidade, e esta é a minha inocência. É que eu sempre achei que o Cinema falava de $90 \%$ da humanidade e foi estúpido. Ainda acho, porque eu acho que o que se passa nas Fontainhas é o que se passa na Índia, na América Latina, na Ásia em geral, na África toda (...). Eu sempre pensei e acreditei que o Cinema é feito para estes $90 \%$ e sempre foi, não posso estar tão enganado. ${ }^{7}$

\section{Nós VERSUS ELES E O PESO DO PASSADO}

Durante as discussões registámos o esforço de aprofundamento dos temas levantados por Cavalo Dinheiro. Por exemplo, como se o elevador onde Ventura se confronta com as suas memórias e os seus medos não fosse apenas o mundo ou a cabeça de Ventura, mas também uma metáfora válida para todos os humanos.

Agnes - Todo o mundo é prisioneiro... nós somos prisioneiros de nós mesmos, dentro da gente tem os nossos medos, os nossos, as nossas alegrias e tristezas, e às vezes isso fica para sempre... só a gente sabe, então... não sei... eu fiz essa interpretação, principalmente desse personagem Ventura. No final eu não entendi muito bem se ele realmente estava conversando com o soldado ou se ele estava imaginando aquela conversa. Então eu entendi que ele estava imaginando a conversa... porque todos temos fantasmas... e os fantasmas na cabeça dele fazem com que ele crie uma situação que para ele é real, para mim que estava a assistir ao filme era pura ilusão. É um pouco difícil. Como a própria vida. (Grupo Focal sobre Cavalo Dinheiro)

Manuel - Há aqui um sentido universal muito vincado... isto por acaso é uma história em Portugal e de imigrantes, mas podia ser de muitas outras comunidades, que sofrem agruras de uma revolução, mal resolvida, colonialismo e todas as consequências que veem por aí fora... (Grupo Focal sobre Cavalo Dinheiro)

Os problemas levantados por Li ké terra foram, com frequência, lidos como consequências da História. Nestes casos, os participantes tenderam a naturalizar o racismo dos nossos dias, ou a considerá-lo uma coisa inevitável.

\footnotetext{
${ }^{6}$ Entrevista cedida a André Dias (2008) "Aquela é a minha terra", Visão, $n^{\circ} 416$.

7 Entrevista cedida a Martin Paradelo e Xiana Arias (s.d.): "eu acho que há cineastas que não têm a coragem de não fazer filmes".
} 
Lídia - Porque a raça negra foi sempre associada a pessoas que trabalham nos lugares mais baixos da sociedade, são os mais pobres, os que têm que fazer o que nós mandamos.

Clara - Isto tem a ver com a História do Mundo.

Lídia - É tudo. Somos o resultado de alguma coisa. (Grupo Focal sobre Li ké terra)

Também observámos uma certa tendência para fazer aproximações aos filmes por identificação com as personagens principais, o que é surpreendente dada a distância (física e simbólica) entre os participantes e as realidades retratadas nos filmes. Sublinhamos que os participantes são quase todos brancos ${ }^{8}$, e vivem numa região do país distante de Lisboa e dos seus subúrbios. É também importante lembrar que as comunidades negras no norte de Portugal são pequenas, raras e não particularmente presentes nos meios de comunicação social. Esta identificação com os protagonistas dos filmes endossa, contudo, sentimentos e crenças distintas.

Vendo Cavalo Dinheiro, os participantes tendem a deixar para trás as diferenças entre eles (e as suas famílias) e as personagens:

Sandra - Esta é exatamente a mesma história do meu avô. Ele foi para França à procura de uma vida melhor, e eles viviam em lugares onde só viviam portugueses, e sem nenhumas condições. (Grupo Focal sobre Cavalo Dinheiro)

Rita - O meu tio esteve na Guerra Colonial e agora teve um AVC e a única coisa que ele fala é das bombas e do barulho e de matar pessoas... e é muito interessante ver este outro lado onde a realidade acaba por ser um bocado sobreposta por toda uma história do passado, que nem sequer chega a nós completa. Há uma parte que chega a nós e há outra coisa que é só uma identidade que se criou com todos os acontecimentos. (Grupo Focal sobre Cavalo Dinheiro)

Vendo Li ké terra, a identificação aparece com frequência para justificar o racismo como uma coisa que acontece em todos os lugares, ou para dizer que os imigrantes em Portugal têm que encontrar o seu próprio caminho como os portugueses fizeram no estrangeiro.

João - Mas, mesmo nós lá fora, como emigran-

tes, também somos tratados assim.

Carla - Olha que não!

\footnotetext{
${ }^{8}$ Em Portugal não existe recolha de dados étnico-raciais, por isso não é possível saber a percentagem de pessoas não-brancas, mas as estimativas indicam que a grande maioria dos afrodescendentes vivem na região de Lisboa. Sobre este assunto ver Roldão (2015) e Arenas (2015).
} 
João - Os meus tios e os meus avós foram todos tratados assim! Agora já não, mas no início quando vão para lá são todos muito rejeitados.

Luísa - Há mesmo muita xenofobia, tanto cá como lá! (Grupo focal sobre Li ké terra)

\section{ESTEREÓTIPOS, ESSENCIALIZAÇÃo Do “OUTRo” E CONSTRUÇÃo POSITIVA DO SELF}

Os participantes nos grupos focais reconheceram a persistência de racismo na sociedade portuguesa. Os participantes mais jovens não tinham conhecimento das dificuldades que jovens de origem Africana enfrentam para obter a cidadania portuguesa, mas reconheceram essas dificuldades como um problema e como uma injustiça. Talvez devido à diferença de idades e de nível de formação entre os participantes, nos grupos relativos a Cavalo Dinheiro os participantes foram muito mais duros no que se refere ao assunto racismo.

Clara - Eu acho que há muita discriminação, nesses aspetos. Pode ser um bocadinho por eles terem os pais de outra nacionalidade, acho que os desloca um bocadinho da sociedade. Eles sentem isso.

Ana - Acho que eles se sentem assim... um bocado deslocados! Apesar de quererem ser portugueses, sentem que não são de cá, que são de outro sítio.

Mariana - Há sempre algumas coisas que os liga a Cabo Verde e isso sente-se na vida deles.

Ana - E as pessoas fazem questão de relembrá-los sempre disso... (Grupo Focal sobre Li ké terra)

Amílcar - Isto é o que acontece agora em muitas situações: eles (os imigrantes) são explorados, e não recebem... eles não têm documentos, eles não têm nada, não podem recorrer a ninguém porque estão ilegais... explorados... eles são explorados. (Grupo Focal sobre Cavalo Dinheiro)

Patrícia - Os brancos são os opressores, no filme somos mostrados como os opressores.... na altura explorávamos demasiado as raças que considerávamos inferiores à nossa neste caso os negros... e que os considerávamos não de uma inteligência menor, mas que não compreendiam tão bem como é que era o mundo e, portanto, nós usufruíamos dessa sua ignorância. (Grupo Focal sobre Cavalo Dinheiro)

Convergindo com estudos (Burke, 2004; Karlins, Thomas \& Walters, 1969; Madon et al., 2001) que demonstram a prevalência da atribuição de estereótipos negativos a 
pessoas negras, durante as discussões sobre Li ké terra, imagens de pessoas negras como musicais, barulhentas, grosseiras e despreocupadas com a vida - "happy-go-lucky" - marcaram presença no discurso de alguns participantes.

Carlos - Estavam despreocupados com a vida (...) um deles estava há três anos sem fazer nada.

Jorge - Acho que o primeiro que não fazia nada ainda ti-

nha a preocupação de procurar como se legalizar no país.

Pedro - Oh, mas esse tem mais tempo...

Jorge - Mas enquanto um se dava ao trabalho de tentar construir os papéis o outro não fazia nada. (Grupo Focal sobre Li ké terra)

Ana - Vão ter mais dificuldades em arranjar emprego, porque além de serem de outras nacionalidades, não têm muita escolaridade, comparando com pessoas que tiveram a sua formação na escola e são mesmo portugueses.

Jorge - Como eles são de cor negra, muitas vezes as pessoas dizem que eles são vândalos, que são daqueles que roubam e tratam-nos mal. Às vezes não é isso. (Grupo Focal sobre Li ké terra)

Outros estereótipos sobre pessoas negras, em geral e sobre cabo-verdianos em particular, nomeadamente considerando que são agressivos, foram chamados à discussão sobre Cavalo Dinheiro. Os participantes parecem estar conscientes da existência de estereótipos mostrando, por vezes discordância, mas outras procurando justificações. Palavras como "revolta" aparecem associadas a negros:

Fausto - Só que há sempre aquela parte. Pronto aqueles problemas que aconteceram aqui há uns anos atrás nos bairros na Damaia... e Amadora ${ }^{9} \ldots$ os grupos maioritariamente são negros... associa-se logo a confusão, a rebeldia aos negros, então em Lisboa pior ainda porque há bairros tipicamente negros... eu acho que é um bocadinho também a frustração deles perante a sociedade... é um bocadinho a forma deles também de demonstrarem que estão revoltados de certa forma é um problema de integração. Acho eu. (Grupo Focal sobre Cavalo Dinheiro)

Paradoxalmente, também nas discussões sobre Cavalo Dinheiro, alguns estudantes consideram a comunidade cabo-verdiana mais próxima dos portugueses do que outros africanos. Esta noção tem as suas raízes não apenas na forma como o poder colonial foi exercido no arquipélago (Henriques, 2016; Torgal \& Paulo, 2008), mas também

9 Sublinhe-se que a Damaia pertence à Amadora, mas o estudante não sabe. Ele discorre sobre uma realidade que conhece apenas através dos média. 
nas diferentes vagas migratórias, e diferentes origens socioculturais dos imigrantes de Cabo Verde que chegaram a Portugal - estes imigrantes eram inicialmente pessoas que pertenciam a uma classe média de funcionários do estado colonial ${ }^{10}$. A ideia prevalece mesmo que a comunidade retratada no filme não corresponda ao estereótipo "eles são quase como nós": o processo de diferenciação entre nós e eles faz com que os participantes comparem trabalhadores que vivem na Amadora, com estudantes universitários seus colegas e os coloquem no mesmo todo indivisível de cabo-verdianos.

Ricardo - Não sei se por acaso fomos buscar a cabo-verdiana que é aquela talvez que mais se assemelha à nossa sociedade: conceito de família, religião, a cultura deles é muito semelhante à nossa não sei se foi de propósito... arranjarem uma cultura negra, uma sociedade negra parecida com a nossa e mesmo assim nós rejeitamos, não sei se foi de propósito... ou não...

Anabela - Se calhar para mostrar que a única diferença entre nós e eles é mesmo a questão do tom de pele, não é mais nada...

Belmiro - Porque é assim... grandes comunidades cabo-verdianas aqui em Braga... Guimarães aqui na Universidade do Minho, quer dizer e eles, quer dizer só mesmo o tom de pele, porque quer dizer os costumes... tem uma diferenças, mas... é tudo igual a nós...

Moderadora - Muitos nasceram cá...

Belmiro - Sim... e relação à comunidade angolana ou moçambicana já é muito diferente.

Moderadora - Acham que é muito diferente?

Diana - São um pouco mais diferentes de nós... e creio que como o colega disse eles foram buscar uma raça negra os cabo-verdianos mais parecida com a nossa para mostrar que só mesmo a cor é que é o nosso problema. (Grupo Focal sobre Cavalo Dinheiro)

A cor da pele aparece como o maior problema entre "nós" e "eles", também durante as discussões sobre Li ké terra. O facto de as duas personagens deste filme terem nascido em Portugal foi muito sublinhado pela moderadora do debate, mas a narrativa dos grupos focais persistentemente caiu na ideia de que eles são imigrantes, devido à sua cor de pele. Expressões de racismo relativamente a imigrantes (não apenas negros) podem ser observadas. Estas expressões às vezes destacam diferenças culturais outras são sustentadas por estereótipos sociais negativos.

\footnotetext{
10 Sobre a imigração cabo-verdiana em Portugal, ver Luís Batalha (2004).
} 
Carlos - Mas, agora no caso de Portugal, o por quê de haver discriminação, por exemplo no racismo, eu sou tudo menos racista! Mas, vamos a ver, em $75 \%$ dos casos de assaltos na baixa de Lisboa são feitos por quem? São feitos por imigrantes de leste...

Jorge - Mas isso é consequência da entrada deles na sociedade portuguesa.

Carlos - Mas, uma coisa não justifica a outra.

Tânia - Algumas foram educadas assim não têm culpa, não é "não têm culpa", não conhecem melhor, mas há outras que deviam ser um bocadinho mais compreensivas e eles esforçam-se agora, acho que assim vão ter um futuro melhor do que aqueles que andam aí a roubar. (Grupo Focal sobre Li ké terra)

Os participantes tendem a assumir que a exploração de imigrantes e o racismo está muito disseminado pela Europa, mas que os portugueses se destacam pela sua capacidade de se relacionarem com outros povos. Este retrato dos portugueses como um povo particularmente aberto ao multiculturalismo, tem as suas raízes na simplificação da teoria lusotropicalista do sociólogo Gilberto Freyre, que foi levada a cabo pelo Estado Novo e que foi largamente divulgada através do cinema (Castelo, 1998; Piçarra, 2015). Também a ideia de que o colonialismo português foi "melhor do que os outros colonialismos" esteve presente, durante os debates. Vários autores discutiram a tendência geral para o favoritismo endogrupal (Tajfel, 1982; van Dijk, 1992). Poderíamos dizer que a valorização das características supostas como sendo as dos portugueses é feita em duas frentes: por um lado, não se identificam com africanos porque eles são "imaturos", "desleixados", "preguiçosos", etc., por outro lado, não se veem tão “intolerantes", nem tão "frios" como os outros europeus.

Isabel - Somos gente simpática.

Catarina - Acolhedora.

Luísa - Talvez as tradições. Depende também de onde vieram, porque se vêm de países onde impera a violência e o racismo, etc... Eles vêm para cá muitas vezes para "fugir" da sociedade de lá.

Sandra - Sim, eu acho que somos acolhedores, somos um povo simpático e que as pessoas se integram bem aqui, em geral. (Grupo Focal sobre Li ké terra) 
Christina - A sociedade portuguesa de certa forma... de certa forma pronto... deve ser dos povos que melhor os aceita porque teve uma grande ligação com eles, no passado e daí os soldados que tiveram lá eles sabem no fundo que aquilo são pessoas não são uns animais. E daí os soldados que estão no fundo a retratar alguma ligação próxima que tiveram com os negros, conviveram com eles diretamente. Agora cá de certa forma são, um bocadinho aceites em relação à maioria dos países europeus. (Grupo Focal sobre Cavalo Dinheiro)

\section{ESTRATÉGIAS DISCURSIVAS DE NEGAÇÃO E RENÚNCIA}

Durante as discussões sobre "raça" percebemos que os participantes usaram estratégias reveladas por estudos no campo da análise crítica discursiva (Bonilla-Silva, 2006; van Dijk, 1984, 1993) para evitarem serem percebidos socialmente como racistas. Não cabe aqui desenvolver uma análise crítica deste fenómeno que por si só indica a existência de racismo e também a sua rejeição, pelo menos em termos formais e sociais do contexto em questão. Contudo, é importante sublinhar que pesquisas anteriores (Bonilla-Silva, 2006; Gomes, 2013) indicam que no contexto de conversas ingroup o racismo pode ser expresso de forma mais explícita do que na presença de elementos externos, neste caso, a presença da moderadora.

Os participantes usaram com frequência modos linguísticos, estratégias de retórica e dispositivos técnicos que permitem aos utilizadores articular os quadros mentais e os scripts providenciados pelo pensamento hegemónico. É importante notar que esses marcadores de estilo só podem ser considerados ideológicos por repetição e repetição nos mesmos contextos discursivos (Bonilla-Silva, 2006; van Dijk, 1987). É o uso do mesmo recurso que o torna analisável como expressão de um grupo. As partes do diálogo que transcrevemos são, portanto, meramente exemplificativas das tendências que observamos, mas não pretendem ser exaustivas.

Ideias racistas são tendencialmente expressas numa lógica de sim, mas também não (Bonilla-Silva, 2006). Incorporar no discurso a perspetiva oposta àquela que se quer defender permite defender ideias muito problemáticas do ponto de vista social e colocá-las em termos raciais.

Marta - Eu penso que por vezes há certas pessoas que vêm para Portugal porque pensam que aqui vão ter mais regalias e às vezes vêm só mesmo por causa disso, porque se virmos bem há muitas pessoas que estão por aí, não digo que não haja pessoas que não vêm para aqui à procura de trabalho e uma melhor vida, mas há outras que só veem para se aproveitar. Uma pequena minoria, porque eu não acredito que uma pessoa queira estar sempre dependente de uma pessoa ou isso... Mas penso que agora isso está a mudar e já não acontece tanto... (Grupo Focal sobre Li ké terra) 
Diana - Eu acho que também é os próprios indivíduos imigrantes... mas porque lá está quando eles imigraram para cá havia muito a questão do racismo... e isso claro que ajuda muito a que eles fiquem fechados no grupo...... (Grupo focal sobre Cavalo Dinheiro)

Estratégias de renúncia ou negação, seguidas de uma afirmação racista, estão amplamente presentes nos debates. Eles podem aparecer como uma aparente negação, aparente concessão; transferência ou contraste e são construídos sobre a representação positiva do self e representação negativa do "outro" (van Dijk, 1992). Como um exemplo de aparente negação, observamos a afirmação quase sempre em termos bastante enfáticos de que "eu não sou racista" que permite adicionar a conjunção "mas", à qual segue, por via de regra, uma afirmação muito forte do ponto de vista racial. Como no comentário já transcrito anteriormente:

Carlos - (...) eu sou tudo menos racista! Mas, vamos a ver, em $75 \%$ dos casos de assaltos na baixa de Lisboa são feitos por quem? São feitos por imigrantes de leste... (Grupo Focal sobre Li ké terra)

Um exemplo de aparente concessão seria a declaração dada anteriormente por um estudante do ensino secundário numa discussão sobre Li ké Terra "eu não digo que não há pessoas que vêm aqui à procura de trabalho e de uma vida melhor, mas há outras que só vem aproveitar". Ou de forma ainda mais acusatória:

Alberto - Também há muita gente que trabalha, mas muitos deles acabam por viver de esquemas... (Grupo Focal sobre Cavalo Dinheiro)

Também registámos exemplos de renúncia por transferência e contraste.

Clara - As pessoas mais velhas normalmente são mais [racistas]. Os retornados não tanto, mas a parte que ficou cá em Portugal, desde de pequenos, são um bocado racistas. (Grupo Focal sobre Li ké terra)

Casemiro - (...) quer dizer, nós eramos muito organizados... muito metódicos e eles não... um bocadinho viver assim mesmo por viver, com objetivo nenhum na vida. (Grupo Focal sobre Cavalo Dinheiro)

Outro recurso usado pelos participantes nas discussões é o diminutivo, que lhes permite expressar posições que poderiam de outro modo ser consideradas racistas, sem o parecerem (Bonilla-Silva, 2006). O diminutivo também serve para diminuir e suavizar o racismo na sociedade portuguesa.

Teresa - Acho que os portugueses, às vezes, são um bocadinho "mauzinhos" para as pessoas que precisam de ajuda para se integrarem na comunidade e rejeitam, ou porque é "negro", ou porque... (Grupo Focal sobre Li ké terra) 
Casemiro - Desorganização total, quer dizer... eu acho que é um bocadinho... que eles não eram... mas no fundo o que querem mostrar é que aos olhos dos brancos era um bocadinho por aí (Grupo Focal sobre Cavalo Dinheiro)

A projeção tem sido considerada um instrumento efetivo e bastante comum para a defesa de nós mesmos (Pinto, 2014) e também é uma ferramenta importante na criação de uma identidade "nós" versus "eles". O aspeto mais importante desse dispositivo, para a nossa análise, é que a projeção ajuda-nos a "escapar da culpa e da responsabilidade e a alocar a culpa noutro lugar" (Bonilla-Silva, 2006, p. 64). A projeção assume diferentes formas e graus de refinamento. Pode aparecer de uma forma bastante sofisticada, por exemplo: "pequena minoria, porque não acredito que uma pessoa queira estar sempre dependente de outra pessoa...". Neste comentário sobre Li ké terra, após uma afirmação potencialmente problemática, o participante projeta uma espécie de identificação emocional. No entanto, a projeção geralmente aparece de forma bastante frontal. Nas discussões sobre ambos os filmes, os participantes usaram expressões como a de Paula, uma estudante do ensino secundário durante uma discussão sobre Li ké terra: "os negros é que costumam ser mais racistas". De acordo com van Dijk (1992), a estratégia argumentativa de manutenção da face dispõe de uma bateria forte e complexa de ações semânticas e uma delas consiste especificamente na inversão: colocar o foco na intolerância do "outro". Associada à projeção, aparece a culpabilização das pessoas segregadas pela sua própria condição, presente também de forma explícita em vários comentários:

Gabriela - (...) isso às vezes também podem ser eles que não se abram às pessoas de cá. Por exemplo, um estrangeiro que venha, nós até podemos muito bem acolher, mas ele não se sentir acolhido e não quiser conviver. (Grupo Focal sobre Li ké terra)

Nuno - Há pessoas que, por vezes, acham que apenas a sua religião e a sua cultura é a certa e que não se deve aprender mais sobre as outras...

Marta - Estão fechados na sua própria cultura e não aceitam...

Nuno - Nem visões de outras partes, de outras culturas. (Grupo Focal sobre Li ké terra)

Vasco - (...) associa-se logo a confusão, a rebeldia aos negros, então em Lisboa pior ainda porque há bairros tipicamente negros... eu acho que é um bocadinho também a frustração deles perante a sociedade... é um bocadinho a forma deles também de demonstrarem que estão revoltados de certa forma é um problema de integração. Acho eu. (Grupo Focal sobre Cavalo Dinheiro) 
Parece importante sublinhar que entendemos o racismo como um problema de poder; portanto, as extrapolações nunca são meramente individuais. Ao analisar o racismo como um discurso estrutural, procuramos compreender como as estruturas de poder, dominação e desigualdade dentro de uma sociedade são reproduzidas pela fala. Como Stuart Hall observou (1984, p. 7) "em qualquer sociedade, todos nós fazemos uso constante, de um conjunto de quadros de interpretação e compreensão, muitas vezes de maneira muito prática e inconsciente, e essas coisas por si só, permitem-nos entender o que está a acontecer ao nosso redor, qual é nossa posição e o que provavelmente faremos". As regras da ideologia, como as da gramática, são criadas e aprendidas socialmente e, portanto, as regras de como falar corretamente não são questionadas dentro de seu contexto social, uma vez que são percebidas como "naturais".

\section{CONSIDERAÇÕES FINAIS}

Apesar das sérias limitações de algumas abordagens académicas tradicionais ao estilo de vida das comunidades negras pobres (Murray, 1984) que tendem a culpar as vítimas, mesmo os críticos mais severos dessas abordagens (Bonilla-Silva, 2006) reconhecem que geralmente o isolamento social e cultural de um grupo leva à diferenciação, ao crescimento da coesão e ao fortalecimento da identidade do grupo subalternizado.

Nos filmes analisados, há um forte sentido de identidade de grupo/comunidade por parte das personagens retratadas. A estratégia de construir e afirmar as identidades desses grupos requer a convocação de uma memória coletiva que encontra no cinema uma forma de se tornar memória cultural (Assmann, 2008). Por outro lado, os grupos focais com jovens, entre os 16 e os 21 anos, que vivem no norte de Portugal, sem contacto direto com as comunidades negras do sul do país que os filmes retratam, mostraram que os estereótipos sociais sobre os negros são endossados pelos participantes, embora reconheçam a persistência do preconceito racial na sociedade portuguesa. Durante as discussões dos grupos focais, o peso das representações advindas de um passado colonial foi determinante no diálogo com as imagens que estavam a ser projetadas.

No entanto, os filmes provocam diferentes abordagens. A linguagem cinematográfica de Li ké terra é acessível e os protagonistas são aproximadamente da mesma idade que os participantes dos grupos focais, portanto, poderia ser fácil para os participantes identificarem-se com eles, embora vários participantes pareçam avalizar estereótipos relacionados à inércia percebida, ou falta de preocupação das personagens. A primeira reação dos participantes a Cavalo Dinheiro é muitas vezes a confissão de que não o entendem - devido à sua duração, à sua complexidade narrativa, ou à distância que os participantes têm das referências históricas e cinematográficas que o filme invoca - mas uma vez encontrada a "chave emocional para entrar" no filme, os participantes tendem a não culpar as personagens pela situação de exploração a que estão sujeitas e nunca se colocam numa posição em que "isso não poderia acontecer comigo". Isto acontece, acreditamos, por razões especificamente cinematográficas, por exemplo, o ângulo - contre-plongée - muitas vezes escolhido para filmar Ventura e Vitalina, o que lhes confere um caráter nobre, respeitável e fascinante. Também o tom poético dos diálogos, a música e 
o silêncio que o filme requer levam a uma leitura das personagens como arquétipos mais do que "os outros" que vivem nos bairros degradados. A forma como os "portugueses", os "patrões" são claramente apontados, em Cavalo Dinheiro é diferente do discurso usado por Li ké terra que se refere a uma exclusão perpetrada pelo sistema, sem nunca abordar diretamente a questão do racismo institucional. No primeiro caso, impõe-se uma situação na qual claramente alguns foram "explorados", "enganados", o segundo permite justificativas políticas para a segregação. Essa postura política diferente leva, acreditamos, a uma diferença na forma como os participantes leem "raças" nos dois filmes.

Convergindo com outros estudos (Cabecinhas, 2007; Macedo, 2017; Vala \& Pereira, 2012), a análise das discussões dos grupos focais revela a persistência de estereótipos negativos sobre os imigrantes africanos e seus descendentes, indicando que o passado colonial continua a influenciar o imaginário e as identidades sociais dos jovens. À semeIhança de outros estudos realizados em Portugal e noutros países europeus (Howard, 2009, 2011), também percebemos que os participantes reproduzem os códigos comunicativos da ideologia hegemónica sobre raça e usam os quadros comunicativos que lhes permitem expressar o racismo sem aparecer socialmente como racistas.

Os estudantes portugueses que participaram nos grupos focais estão abertos à discussão sobre o passado colonial e as suas consequências no presente, mas não estão familiarizados com este período histórico. O racismo na sociedade portuguesa apenas recentemente começou a ser objeto de discussão na esfera pública. O cinema pode desempenhar um papel central no desafio às representações hegemónicas e promover a mudança social. Apesar da "inércia notável" (Wagner, Holtz \& Kashima, 2009, p. 376) dos sistemas de significado cultural, os estereótipos sociais sobre grupos não são estáticos; a sua mudança depende do interesse político que é a base da dinâmica social.

\section{Tradução: Ana Cristina Pereira}

\section{FinANCIAMENTO}

Artigo desenvolvido no contexto do projeto "Memories, cultures and identities: how the past weights on the present-day intercultural relations in Mozambique and Portugal?", financiado pela Rede Aga Khan para o Desenvolvimento e pela Fundação para a Ciência e Tecnologia.

\section{REFERÊNCIAS}

Anderson, B. (1983). Imagined communities: reflections on the origin and spread of nationalism. Londres: Verso.

Arenas, F. (2015). Migrations and the Rise of African Lisbon: Time Space of Portuguese (Post)coloniality. Postcolonial Studies, 18(4), 353-366.

Assmann, J. (2008). Communicative and cultural memory. In A. Erll \& A. Nünning, Cultural Memory Studies. An International and interdisciplinary handbook (pp. 109-118). Berlim: Walter de Gruyter.

Bauman, Z. (2004). Identity conversations with Benedeto Vecchi/Zygmunt Bauman. Cambridge: Polity Press. 
Baptista, T. (2011). Depois do cinema português. Covilhã: Livros LabCom 5-20.

Bhabha, H. (1994). The location of culture. Nova lorque: Routledge.

Batalha, L. (2004). The Cape Verdean diaspora in Portugal: colonial subjects in a postcolonial world. Lanham, MD: Lexington Books.

Bonilla-Silva, E. (2006). Racism without racists: colour blind racism and the persistence of racial inequality in the United States. Maryland: Rowman \& Littlefield Publishers.

Burke, P. (2004). Estereótipos do Outro. Testemunha ocular: história e imagem. Bauru, SP: EDUSC.

Cabecinhas, R. (2007). Preto e branco: a naturalização da discriminação racial Porto: Campo de Letras.

Castelo, C. (1998). "O modo português de estar no mundo", o luso-tropicalismo e a ideologia colonial portuguesa (1933-1961). Porto: Edições Afrontamento.

Costa, P. (Realizador). (2006). Juventude em marcha [Filme]. Portugal: Optec, Portugal.

Costa, P. (Realizador). (2014). Cavalo Dinheiro [Filme]. Portugal: Optec, Portugal.

Dias, A. (2008). Aquela é a minha terra. Visão, 416. Retirado de http://pedrocosta-heroi.blogspot. pt/2008/03/aquela-minha-terra.html

Fivush, R. (2008). Remembering and reminiscing: how individual lives are constructed in family narratives. Memory Studies 1(1), 49-58.

Gomes, S. (2013). Criminalidade, etnicidade e desigualdades: análise comparativa entre os grupos nacionais dos PALOP e Leste Europeu e o grupo ético cigano. Tese de Doutoramento, Universidade do Minho, Braga, Portugal.

Hall, S. (1984). The narrative construction of reality. Southern Review 17, 3-17.

Hall, S. (2005). A Identidade cultural na Pos-Modernidade. Rio de Janeiro: DP\&A Editora.

Hall, S. (1993). Cultural identity and diaspora. Framework, 36, 222-237.

Halpern, M. (2014, 5 de dezembro). Cavalo Dinheiro, de Pedro Costa - Alto Cutelo. Jornal de Letras. Retirado de http://visao.sapo.pt/jornaldeletras/cinema/cavalo-dinheiro-de-pedro-costa-alto-cutelo=f80 3245

Henriques, J. G. (2016). Racismo em Português. Lisboa: Tinta da China.

Howarth, C. (2009). "I hope we won't have to understand racism one day": researching or reproducing "race" in social psychological research? British Journal of Social Psychology, 48(3), 407-426. https://doi. org/10.1348/014466608X360727

Howarth, C. (2011). Representations, identity and resistance in communication. In D. Hook, B. Franks \& M. Bauer, The social psychology of communication (pp. 153-168). Londres: Palgrave.

Karlins, M., Thomas, L. C. \& Walters G. (1969). On the fading of social stereotypes: studies in three generations of college students. Journal of Personality and Social Psychology, 13, 1-16.

Lemière, J. (2006). "Um centro na margem": o caso do cinema português. Análise Social XLI(180), 731-765.

Macedo, I. (2016). Youth and portuguese cinema: the (de)colonisation of the imaginary? Comunicação $e$ Sociedade, 29, 291-309. 
Macedo, I. (2017). Migrações, memória cultural e representações identitárias: a literacia filmica na promoção do diálogo intercultural. Tese de Doutoramento, Universidade do Minho, Braga, Portugal

Madon, S., Guyll, M., Aboufadel, K., Montiel, E., Smith, A., Palumbo, P. \& Jussin, L. (2001). Ethnic and national stereotypes: the Princeton trilogy revisited and revised. Personality and Social Psychology Bulletin, 27(8), 996-1010. https://doi.org/10.1177/0146167201278007

Matos, P. F. (2016). Images of Africa? Portuguese films and documentaries related to the former colonies in Africa (first half of the 2oth century). Comunicação e Sociedade, 29, 153-174.

Mead, L. (1986). Beyond entitlement: the social obligations of citizenship. Nova lorque: Free Press.

Murray, C. (1984). Losing ground: american social policy, 1950-1980. Nova Iorque: Basic.

Oliveira, L. M. (2014, 4 de dezembro). Pedro Costa: cada filme é melhor que o anterior. Publico. Retirado de https://www.publico.pt/culturaipsilon/noticia/preso-neste-elevador-1678267

Paradelo, M. \& Xiana A. (s.d.). Eu acho que há cineastas que não têm a coragem de não fazer filmes. Retirado de http://cineclubedecompostela.blogaliza.org/files/2012/12/entrevista-Costa.pdf

Piçarra, M. C. (2015). Azuis ultramarinos. Propaganda colonial e censura no cinema do Estado Novo. Lisboa: Edições 70.

Pinto, E. R. (2014). Conceitos fundamentais dos métodos projetivos. Ágora, 17(1), 135-153. http://dx.doi. org/10.1590/S1516-14982014000100009

Pinto, F. M. (2011). A integração de Portugal nas comunidades europeias. Dissertação de Mestrado, Universidade de Coimbra, Portugal.

Reis, F., Guerra, J. M. \& Baptista, N. (Realizadores). (2011). Li ké terra [Filme]. Portugal.

Riss, J. (1890). How the other half lives: studies among the tenements of New York. Boston: Bedford/St.Martin's.

Rommery, J. (2015). Film of the week: Horse Money. Filmcomment. Retirado de http://www.filmcomment. com/blog/film-of-the-week-horse-money

Roldão, C. (2015). Fatores e perfis de sucesso escolar "inesperado": trajetos de contratendência de jovens das classes populares e de origem africana. Dissertação de Doutoramento, ISCTE - Instituto Universitário de Lisboa, Portugal.

Tajfel, H. (1982). Grupos humanos e categorias sociais. Lisboa: Livros Horizonte.

Torgal, L. R. \& Paulo, H. (Eds.) (2008). Estados autoritários e totalitários e suas representações. Coimbra: Imprensa da Universidade de Coimbra.

Vala, J. \& Pereira, C. (2012). Racism: an evolving virus. In F. Bethencourt \& A. Pearce (Eds.), Racism and ethnic relations in the Portuguese-speaking world (pp. 49-70). Nova lorque: Oxford University Press.

van Dijk, T. A. (1984). Prejudice in discourse: an analysis of ethnic prejudice in cognitio and conversation. Amsterdam: Benjamins.

van Dijk, T. A. (1992). Text, talk, elites and racism. Discours Social/Social Discourse, 37-62.

van Dijk, T. A. (1993). Analysing racism through discourse analysis: some methodological reflections. In J. Stanfield (Ed.), Race and ethnicity in research methods (pp. 92-134). Newbury Park, CA: Sage. 
Wagner, W., Holtz, P. \& Kashima, Y. (2009). Construction and deconstruction of essence in representing social groups: identity projects, stereotyping, and racism. Journal for the Theory of Social Behaviour, $39(3), 363-393$.

\section{NOTAS BIOGRÁFICAS}

Ana Cristina Pereira aguarda defesa da tese de doutoramento, em Estudos Culturais, intitulada Alteridade e identidade na ficção cinematográfica em Portugal e em Moçambique, desenvolvida na Universidade do Minho, e financiada pela Fundação para a Ciência e a Tecnologia. Licenciada em Estudos Teatrais pela Escola Superior de Teatro e Cinema de Lisboa e pela Escola de Música e Artes do Espetáculo do Porto e mestre em Ciências da Educação pela Universidade de Aveiro. É membro do projeto "Memória, Culturas e Identidades: o passado e o presente das relações interculturais em Moçambique e Portugal", financiado pela Fundação Agakhan e também do projeto "A margem do cinema português: estudo sobre o cinema português afrodescendente produzido em Portugal", financiado pela Fundação Gulbenkian. Tem como principais interesses de investigação: cinema pós-colonial, identidade social, representações sociais, racismo e memória cultural.

ORCID: https://orcid.org/oooo-0002-3698-0042

Email: ana.c.pereira@outlook.com

Morada: Centro de Estudos de Comunicação e Sociedade, Instituto de Ciências Sociais, Universidade do Minho, Campus de Gualtar, 4710-057 Braga, Portugal

Isabel Macedo é doutorada em Estudos Culturais pela Universidade do Minho e Universidade de Aveiro, na área da Comunicação e Cultura. A sua tese de doutoramento intitula-se Migrações, memória cultural e representações identitárias: a literacia fílmica na promoção do diálogo intercultural. É investigadora do Centro de Estudos de Comunicação e Sociedade e integra várias associações nacionais e internacionais na área da comunicação, da educação e da cultura visual. Co-editou a revista Comunicação e Sociedade, dedicada ao tema "Ciências da Comunicação e Estudos Lusófonos", e a vista - Revista de Cultura Visual, intitulada "Memória cultural, imagem, arquivo". Alguns dos seus principais trabalhos são: "Representations of dictatorship in Portuguese cinema" (2017), em co-autoria; "Interwoven migration narratives: identity and social representations in the Lusophone world" (2016), em co-autoria, e "Os jovens e o cinema português: a (des) colonização do imaginário?" (2016).

ORCID: https://orcid.org/oooo-0003-4107-3997

Email: isabel.macedo@ics.uminho.pt

Morada: Centro de Estudos de Comunicação e Sociedade, Instituto de Ciências Sociais, Universidade do Minho, Campus de Gualtar, 4710-057 Braga, Portugal

Rosa Cabecinhas é professora no Departamento de Ciências da Comunicação, Instituto de Ciências Sociais da Universidade do Minho e investigadora do Centro de 
Estudos de Comunicação e Sociedade. Atualmente é diretora do Programa Doutoral em Estudos Culturais na mesma universidade. É autora de vasta obra científica na área da comunicação intercultural.

ORCID: https://orcid.org/oooo-0002-1491-3420

Email: cabecinhas@ics.uminho.pt

Morada: Centro de Estudos de Comunicação e Sociedade, Instituto de Ciências Sociais, Universidade do Minho, Campus de Gualtar, 4710-057 Braga, Portugal

* Submetido: 12-06-2018

* Aceite: 02-01-2019 